\title{
Effect of desensitizing toothpastes on dentin
}

\author{
Shelon Cristina Souza Pinto(a) \\ Camila Maggi Maia Silveira ${ }^{(a)}$ \\ Márcia Thaís Pochapski(a) \\ Gibson Luiz Pilatti(b) \\ Fábio André Santos ${ }^{(b)}$
}

(a) Department of Dentistry, School of Dentistry, Univ Estadual de Ponta Grossa, Ponta Grossa, PR, Brazil.

(b) School of Dentistry, Univ Estadual de Ponta Grossa, Ponta Grossa, PR, Brazil.

Declaration of Interests: The authors certify that they have no commercial or associative interest that represents a conflict of interest in connection with the manuscript.

Corresponding Author:

Fábio André Santos

E-mail: fasantos11@gmail.com

Submitted: May 30, 2012

Accepted for publication: Jul 27, 2012

Last revision: Aug 10, 2012
Abstract: The objective of this study was to analyze the effects of toothbrushing with desensitizing toothpastes on dentin permeability and dentinal tubule occlusion. Fifty rats provided two hundred incisor teeth divided into five groups: DW, brushed with distilled water (control); FT, brushed with fluoride toothpaste; SCT, brushed with strontium chloride toothpaste; PCT, brushed with potassium citrate toothpaste; and PNT, brushed with potassium nitrate toothpaste. Cavities were prepared to expose the dentinal tubules, and the incisor teeth were brushed using the experimental agents. After each treatment, Evans blue dye solution was applied to the teeth. Dentin permeability was analyzed using scanning electron microscopy and energy-dispersive X-rays (EDX). There were significant differences $(\mathrm{p}<0.0001$, ANOVA) among the groups regarding dentin permeability, number of dentinal tubules, diameter of dentinal tubules, and opened tubular area. In the SCT, PCT and PNT groups, opened and partially occluded tubules, deposits, and a few smear layers were observed. In the DW and FT groups, most of the dentinal tubules were open, with no deposits or smear layers on the dentin. EDX revealed peaks of calcium and phosphorus in all of the groups, as well as traces of strontium in the SCT group and of potassium in the PCT and PNT groups. Desensitizing toothpaste decreased dentin permeability, although it produced only partial dentin tubule occlusion.

Descriptors: Dentin Desensitizing Agents; Toothpastes; Toothbrushing.

\section{Introduction}

The improvement of oral health is necessary for the reduction of caries and for long-term tooth maintenance. However, oral hygiene procedures can also contribute to tooth wear, mainly when they are performed in areas with exposed dentin. Dentin hypersensitivity $(\mathrm{DH})$ is neither a recent problem nor a rare one; nonetheless, this clinical condition remains poorly understood with no effective or permanent treatment available. ${ }^{1,2}$

DH is clinically described as a painful response to thermic, chemical, mechanical, evaporative, or osmotic stimuli applied to opened dentinal tubules, which cannot be ascribed to any other form of dental defect or pathology. ${ }^{1,3}$

The dentinal tubules play an important role in transferring stimuli and irritants to the pulp. The hydrodynamic theory of dentin sensitivity postulates a flow of fluid through the tubule as the transducing mechanism for hydrodynamic stimuli. ${ }^{2-4}$ It has been demonstrated that hyper- 
sensitive dentin has a larger number of wide, opened dentinal tubules on the surface than does non-sensitive dentin. ${ }^{5}$ A rational approach to the control of pain arising from exposed dentin would thus be to block the tubules or to reduce their diameter..$^{5-8}$

Ideally, a treatment for dentin hypersensitivity, as well as for other problems, should be quick and simple. Thus, the use of special toothpastes has been largely embraced as one of the first alternatives. They are non-invasive and easily available (in drugstores and supermarkets), and according to some studies, they have a good cost-benefit ratio, especially compared to professional appointments. ${ }^{1,2,4,5,8-11}$

Dentinal tubule occlusion in humans, at present, can only be evaluated by extraction, replication or dentin biopsy, all of which have their own problems and limitations. Animal models provide a better option for studying the action of desensitizing agents on dentin. Thus, the purpose of this study was to compare the effects of desensitizing toothpastes, in combination with toothbrushing, on dentin permeability and on dentinal tubule occlusion in rats.

\section{Methodology}

Fifty rats provided two hundred teeth (upper and lower incisors) for the study (Research Ethics Committee: \#629006). The animals were divided into five groups ( $\mathrm{n}=10$ rats per group):

- DW, brushed with distilled water (control);

- FT, brushed with 1500 ppm fluoride toothpaste;

- SCT, brushed with 10\% strontium chloride toothpaste;

- PCT, brushed with $5.5 \%$ potassium citrate toothpaste; and

- PNT, brushed with $5.0 \%$ potassium nitrate toothpaste.

The toothpaste compositions are summarized in Table 1.

The animals were anesthetized with an intraperitoneal injection (ketamine $75 \mathrm{mg} / \mathrm{kg}$ and xylazine $10 \mathrm{mg} / \mathrm{kg}$ ). Cavities $0.3 \mathrm{~mm}$ in depth and $0.8 \mathrm{~mm}$ in width were prepared on the buccal surfaces (cervical region) of the upper and lower incisors (forty teeth per group) using a standard (active tip with $0.3 \mathrm{~mm}$ ) \#245 carbide burr (S.S. White, Rio de Janeiro, Brazil). ${ }^{7}$ Prior to the treatments, the dentin of all of the cavities was treated with 24\% EDTA gel (Biodinâmica Química e Farmacêutica, Ibiporã, Brazil) on tiny cotton pellets, which were replaced every $30 \mathrm{~s}$ for $3 \mathrm{~min}$ to remove the smear layer and to open the dentinal tubules. ${ }^{12}$

The teeth were brushed with a children's toothbrush (Colgate Kids ${ }^{\circledR}$, São Paulo, Brazil) using the experimental agents (tests: $2 \mathrm{~g}$ of the toothpaste with $1 \mathrm{~mL}$ of distilled water; control: $2 \mathrm{~mL}$ of distilled water). This procedure was performed once daily for 4 days. After each daily treatment, $5 \mu \mathrm{L}$ of $5 \%$ Evans blue dye solution (Merck Chemical, Darmstadt, Germany) was applied with a dropping pipette onto each dentin cavity and was left to penetrate for $5 \mathrm{~min}$.

Fifteen toothbrushing movements were applied, based on clinical aspects, because fifteen is the normal number of movements performed during toothbrushing per tooth. The force for toothbrushing was

\begin{tabular}{|c|c|c|c|c|}
\hline \multirow{5}{*}{$\begin{array}{r}\text { Table } 1 \text { - Toothpastes used in } \\
\text { the study. }\end{array}$} & Group & Toothpaste & Active ingredients & Company \\
\hline & FT & Colgate Tripla Ação ${ }^{\circledR}$ & $\begin{array}{l}\text { Sodium monofluorophosphate } \\
\text { (1500 ppm fluoride), calcium carbonate, } \\
\text { sodium silicate, sodium bicarbonate }\end{array}$ & $\begin{array}{l}\text { Colgate-Palmolive, } \\
\text { São Paulo, Brazil }\end{array}$ \\
\hline & $\mathrm{SCT}$ & Sensodyne Original ${ }^{\circledR}$ & $\begin{array}{l}10 \% \text { strontium chloride hexahydrate, } \\
\text { silica, titanium dioxide, calcium } \\
\text { carbonate }\end{array}$ & $\begin{array}{l}\text { GlaxoSmithKline, } \\
\text { Rio de Janeiro, Brazil }\end{array}$ \\
\hline & PCT & $\begin{array}{l}\text { Colgate Sensitive } \\
\text { Branqueador }^{\circledR}\end{array}$ & $\begin{array}{l}5.04 \% \text { potassium citrate, sodium } \\
\text { monofluoro-phosphate ( } 1450 \text { ppm } \\
\text { fluoride), silica, titanium dioxide }\end{array}$ & $\begin{array}{l}\text { Colgate-Palmolive, } \\
\text { São Paulo, Brazil }\end{array}$ \\
\hline & PNT & SensodyneProteção Total ${ }^{\circledR}$ & $\begin{array}{l}5.0 \% \text { potassium nitrate, triclosan, silica, } \\
\text { titanium dioxide, calcium carbonate }\end{array}$ & $\begin{array}{l}\text { GlaxoSmithKline, } \\
\text { Rio de Janeiro, Brazil }\end{array}$ \\
\hline
\end{tabular}


applied by the same examiner, and this force was calibrated.

At the end of experiment, the rats were sacrificed, and the teeth were carefully extracted.

\section{Dentin permeability analysis}

Five percent by weight Evans blue solution was employed to analyze the dentin permeability (20 teeth per group). The samples were embedded in epoxy resin and were sectioned longitudinally (buccal-lingual direction) using a water-cooled diamond saw (ISOMET 1000 Precision Saw, Buehler, Lake Bluff, USA).

The samples were photographed (Microscope Olympus ${ }^{\circledR}$ BX41, Olympus, Tokyo, Japan) at $40 \times$ magnification, and images of 5.1 megapixels (Olympus Camedia C-5060, Tokyo, Japan) were obtained. The image analysis software used was Image Pro Plus ${ }^{\circledR}$, version 4.5 (Media Cybernetics, Silver Spring, USA). Each image was calibrated individually using a standard scale $(\mu \mathrm{m})$. Three measurements (upper, middle and lower region in the analyzed area) were taken for each image, indicating the depth of the dye infiltration (length of dye penetration), and a mean was calculated for each specimen. The same examiner performed all of the measurements.

\section{Scanning electron microscopy (SEM)}

A total of 20 teeth per group were evaluated by SEM. All of the specimens were transversely sectioned using a water-cooled diamond saw. The sectioned specimens were washed with $20 \mathrm{~mL}$ of distilled water and were ultrasonicated for $10 \mathrm{~min}$. Dehydration was achieved to the critical point of dryness using a graded series of ethanol $(25 \%$, $50 \%, 70 \%, 90 \%$ and $100 \%$ for $10 \mathrm{~min} / \mathrm{each})$. The specimens were mounted on metal stubs, kept in a $37^{\circ} \mathrm{C}$ stove for $24 \mathrm{~h}$ and stored in a vacuum silica gel desiccator for $48 \mathrm{~h}$. To perform the SEM analysis, the samples were sputter coated with $25 \mathrm{~nm}$ of gold for $10 \mathrm{~min}$.

Nine images from each sample (central area) were obtained by SEM (Shimadzu SSX 550 ${ }^{\circledR}$, Shimadzu do Brasil, São Paulo, Brazil), operated at $20 \mathrm{kV}$ with $1,000 \times$ and $3,000 \times$ magnification. The SEM photomicrographs were evaluated quantita- tively and qualitatively. The quantitative analysis was performed by counting the number of dentinal tubules and obtaining an estimate per $\mathrm{mm}^{2}$, considering a total area of $1,600 \mu \mathrm{m}^{2}$, of the diameter of dentinal tubules and the opened tubular area using Image Pro Plus ${ }^{\circledR}$ software. The qualitative evaluation considered dentin surface characteristics, intertubular and peritubular dentin, dentinal tubules and smear layer deposits.

\section{Energy-dispersive X-ray (EDX)}

The samples were examined by energy-dispersive X-ray microanalysis (Shimadzu SSX $550^{\circledR}$, Shimadzu do Brasil, São Paulo, Brazil) to determine the presence of chemical elements in deposits found next to the dentinal tubules of each specimen. The spectrum was obtained at $20 \mathrm{kV}$, with a spot size of $5 \mathrm{~nm}$ and a counting time of $300 \mathrm{~s}$. This procedure provided qualitative information about the presence of fluorine $(\mathrm{F})$, sodium $(\mathrm{Na})$, magnesium $(\mathrm{Mg})$, silicon $(\mathrm{Si})$, phosphorus $(\mathrm{P})$, potassium $(\mathrm{K})$, strontium $(\mathrm{Sr})$ and calcium $(\mathrm{Ca})$.

\section{Statistical analysis}

Intra-examiner reproducibility (dentinal permeability, tubule number, tubule diameter and tubule area) was tested with intraclass correlation coefficients (ICC). Comparisons among the groups regarding dentin permeability and tubule number, diameter and area were performed by one-way ANOVA and Bonferroni's post hoc test (GraphPad Prism $^{\mathrm{TM}}$ 5.01, San Diego, USA). The significance levels were set at $\alpha=5 \%(\mathrm{p} \leq 0.05)$.

\section{Results \\ Reproducibility}

The intra-examiner intraclass correlation coefficients (ICC) were 0.98 for dentinal permeability, 0.99 for tubule quantity, 0.97 for tubule diameter and 0.99 for tubule area (good reliability).

\section{Dentin permeability}

The means and SDs of dentin permeability are shown in Table 2. There were significant differences among the groups $(\mathrm{p}<0.0001)$. 
Table 2 - Mean and standard deviation of dentin permeability

(5\% Evans blue dye) and number and diameter area of dentinal tubules after treatment. DW, control; FT, fluoride toothpaste; SCT, strontium chloride toothpaste; PCT, potassium citrate toothpaste; PNT, potassium nitrate toothpaste.

\begin{tabular}{c|c|c|c|c}
\hline \multirow{2}{*}{ Groups } & \multicolumn{4}{|c}{ Parameters } \\
\cline { 2 - 5 } & $\begin{array}{c}\text { Dentin permeability } \\
(\mu \mathrm{m})\end{array}$ & $\begin{array}{c}\text { Number of dentinal } \\
\text { tubules }\left(1000 / \mathrm{mm}^{2}\right)\end{array}$ & $\begin{array}{c}\text { Diameter of dentinal } \\
\text { tubules }(\mu \mathrm{m})\end{array}$ & $\begin{array}{c}\text { Area of dentinal } \\
\text { tubules }\left(\mu \mathrm{m}^{2}\right)\end{array}$ \\
\hline DW & $398.40 \pm 180.90^{\mathrm{b}}$ & $73.13 \pm 26.23^{\mathrm{b}}$ & $1.26 \pm 0.25^{\mathrm{b}}$ & $71.16 \pm 19.83^{\mathrm{a}}$ \\
\hline FT & $302.20 \pm 131.60^{\mathrm{b}}$ & $30.43 \pm 7.72^{\mathrm{a}}$ & $1.36 \pm 0.25^{\mathrm{b}}$ & $26.27 \pm 8.96^{\mathrm{b}}$ \\
\hline SCT & $86.19 \pm 61.19^{\mathrm{a}}$ & $23.16 \pm 6.67^{\mathrm{a}}$ & $0.93 \pm 0.22^{\mathrm{a}}$ & $13.11 \pm 7.31^{\circ}$ \\
\hline PCT & $90.02 \pm 55.73^{\mathrm{a}}$ & $24.33 \pm 5.80^{\mathrm{a}}$ & $0.96 \pm 0.20^{\mathrm{a}}$ & $13.69 \pm 6.70^{\mathrm{a}}$ \\
\hline PNT & $69.03 \pm 55.16^{\mathrm{a}}$ & $25.92 \pm 7.64^{\mathrm{a}}$ & $0.88 \pm 0.24^{\mathrm{a}}$ & $14.27 \pm 9.62^{\mathrm{a}}$ \\
\hline
\end{tabular}

Vertically, different letters denote significant differences $(p<0.01$ ) in each parameter (ANOVA and Bonferroni's post hoc tests).

\section{Scanning electron microscopy (SEM)}

The values of the dentinal tubules per $\mathrm{mm}^{2}$, the diameter, and the area exhibited significant differences $(\mathrm{p}<0.0001)$ among the groups (Table 2$)$.

The qualitative analysis showed the presence of open and partially occluded tubules, peritubular and intertubular deposits, and a few smear layers in the SCT, PCT and PNT groups. In the DW and FT groups, most of the dentinal tubules were opened, with neither deposits nor smear layers on the peritubular and intratubular dentin (Figure 1).

\section{Energy-dispersive X-ray (EDX)}

EDX analysis revealed peaks of chemical elements found on both the experimental and control samples (Figure 1).

\section{Discussion}

Dentin hypersensitivity in humans can, at present, only be evaluated by extraction, replication or dentin biopsy, all of which have problems and limitations. Animals provide a better option for studying the action of desensitizing agents on dentin. The present study, therefore, used rats because of the ease of obtaining samples and of reproducing oral characteristics comparable to those of humans. The cervical area of the incisors was analyzed because it was more appropriate, due to their greater number of dentinal tubules. ${ }^{13-15}$

The analysis of dentin permeability in this study showed higher dentin permeability in the DW and FT groups. The SCT, PCT and PNT groups had lower dentin permeability. Studies in vitro and in vivo have shown a reduction of dye penetration af- ter the application of desensitizing agents. ${ }^{3,7}$ Analysis of dentin permeability using dye diffusion in animal models was deemed appropriate considering the objectives of this study. There is no way to reproduce satisfactorily the pulpar pressure, although other studies have attempted to do so using hydraulic conductivity to analyze dentin permeability., ${ }^{4,516}$ While this method does indeed apply constant pressure in an attempt to simulate normal pulpar conditions, it cannot reproduce other crucial factors, such as oral temperature, saliva flow, dental biofilm, and mastication.

This present research showed that the control group had a higher number of opened dentinal tubules; the other experimental groups had lower numbers of opened dentinal tubules, perhaps due to the action of desensitizing and abrasive agents occluding the tubules in the current results. The number of dentinal tubules ranges from $21,000 / \mathrm{mm}^{2}$ to $48,000 / \mathrm{mm}^{2}$ in human dentin, at a position halfway between the pulp and enamel.6,7,15 In this present study, after brushing with different toothpastes, the number of dentin tubules ranged from $23,160 / \mathrm{mm}^{2}$ to $30,430 / \mathrm{mm}^{2}$. These results are very similar to those of other studies using desensitizing agents on rat teeth and on human dentin. ${ }^{7,17}$

The dentin tubule diameter was smallest in teeth that were brushed with desensitizing toothpastes. These results obtained in the SCT, PCT and PNT groups were probably due to the action of desensitizing, in combination with abrasive agents, resulting in higher number of partially obliterated tubules. The rat incisors in the current study showed a dentin tubule diameter ranging from 0.88 to $1.36 \mu \mathrm{m}$. 

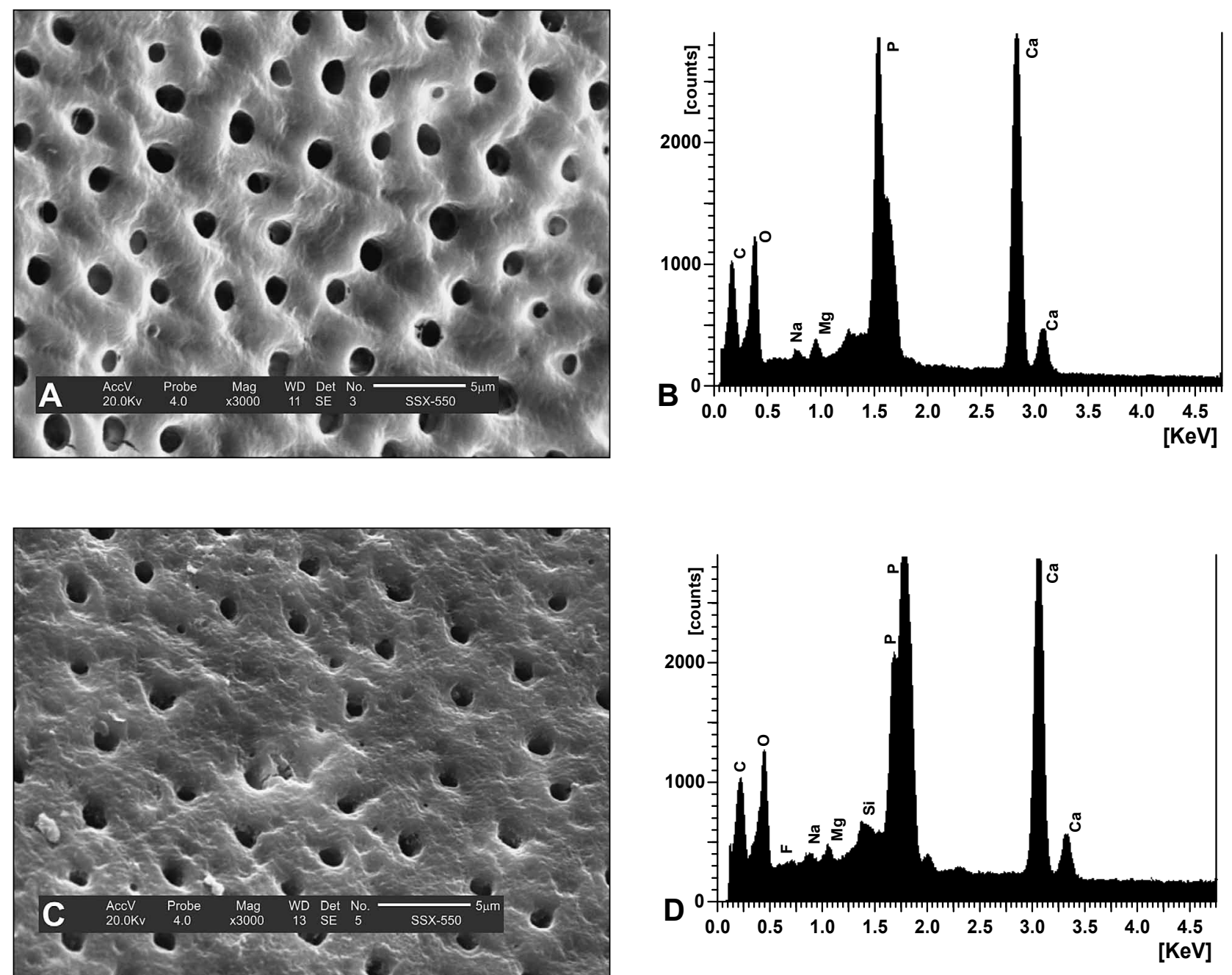

Figure 1 - SEM photomicrographs and the EDX spectrum of the dentin surface after treatments. DW, control: (A) Most of the dentinal tubules were opened, with neither deposits nor smear layers on the peritubular and intratubular dentin. (B) Presence of $\mathrm{P}, \mathrm{Ca}, \mathrm{Na}$ and $\mathrm{Mg}$. FT, fluoride toothpaste: (C) Features similar to those found in DW, with opened dentinal tubules and no deposits or smear layers. (D) presence of $\mathrm{P}, \mathrm{Ca}, \mathrm{Na}, \mathrm{Si}$, and $\mathrm{Mg}$ and traces of $\mathrm{F}$. [continued on next page]

These values are lower than those in other studies that reported dentin tubule diameter in rats, but in those studies, the dentin remained untreated., ${ }^{713-15}$ The differences among studies might be related to the different chemical agents (desensitizing or abrasives) applied to the dentin.

The dentinal tubule area exhibited significant differences among the groups. These findings showed $4.45 \%, 1.64 \%, 0.82 \%, 0.85 \%$ and $0.89 \%$ of the dentin area occupied by opened tubules in the DW, FT, SCT, PCT and PNT groups, respectively. In humans, it is possible to find $6 \%$ of the dentin area occupied by tubules at a distance halfway be- tween the pulp and enamel. ${ }^{18}$ Rat incisors showed $4 \%$ to $11 \%$ of the corresponding area occupied by tubules. ${ }^{14,15}$ The percentage of the area occupied by dentinal tubules in this study was probably lower due to the use of the toothpastes, which can occlude many tubule orifices. The decreased dentinal tubule diameter in the control group could have been due to the normal presence of minerals in saliva; this factor probably contributes to a reduction in dentin sensitivity. ${ }^{4,16}$

The samples from the SCT, PCT and PNT groups had dentin tubules that were partially occluded, and there were fewer deposits or smear lay- 

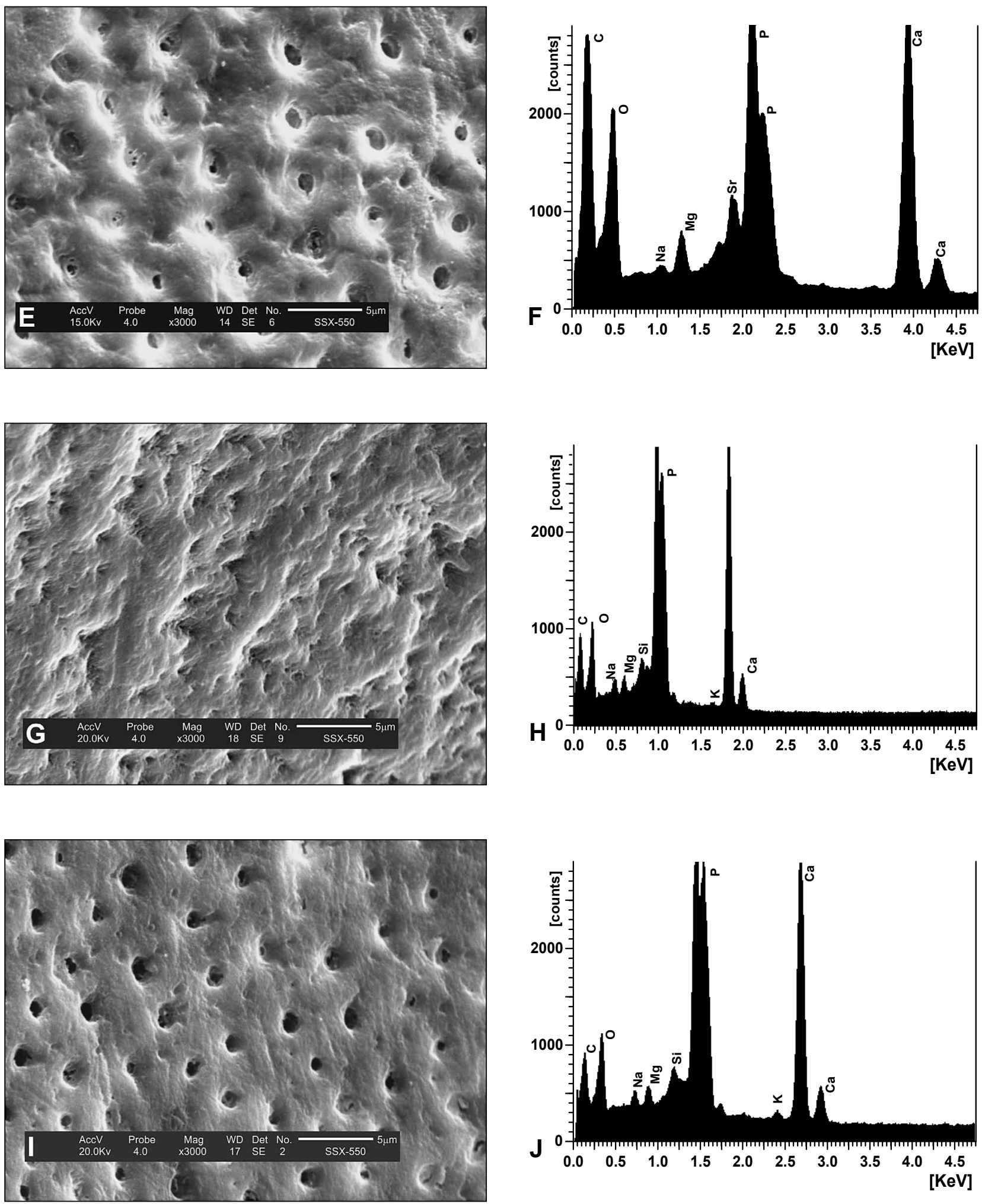

Figure 1 [continued] - SCT, strontium chloride toothpaste: (E) Presence of opened and partially occluded tubules, deposits and some smear layers on the dentin. (F) Presence of $\mathrm{Sr}, \mathrm{Na}, \mathrm{Ca}$ and Mg. PCT, potassium citrate toothpaste: (G) Presence of opened and partially occluded tubules. (H) Low quantity of $\mathrm{K}$ and presence of $\mathrm{Na}, \mathrm{Si}, \mathrm{Ca}$ and $\mathrm{Mg}$. PNT, potassium nitrate toothpaste: (I) Open and partially occluded tubules. (J) Traces of $\mathrm{K}$ and presence of $\mathrm{Na}, \mathrm{Si}, \mathrm{Ca}$ and $\mathrm{Mg}$. 
ers on their peritubular and intertubular dentin. In the DW and FT groups, the majority of dentin tubules were open, and there were no smear layer deposits. Similar results have been observed using fluoridated toothpastes, with no differences between in vitro and in vivo studies when toothbrushing with water was used as a control. ${ }^{1,5}$

The dentifrices used in this study were chosen based on their different compositions of desensitizing agents. Potassium citrate and potassium nitrate desensitizing agents are added to toothpastes to interrupt the neural response to painful stimuli. ${ }^{2}$ In contrast, strontium can be absorbed by the enamel and dentin, and it acts by improving fluoride's effects and by occluding dentinal tubules. ${ }^{11}$ However, the real effects attributable to strontium still remain unclear. $^{2}$

According to these results, strontium chloride, potassium citrate, and potassium nitrate associated with abrasive agents were able to reduce dentin permeability when compared to brushing with fluoride toothpaste or distilled water. Generally, the retention of abrasive particles is relatively poor; however, silica possesses considerable uptake and occlusion powers and is not easily dislodged by water, let alone by acids. ${ }^{8}$ This retention could be the result of hydroxyl groups' binding of artificial silica to the calcium receptors on the dentin surface; natural silica, being inert, would not display such ionic interactions. Citrates have the ability to chelate calcium. Hence, it is possible that tubular occlusion could occur with these pastes, resulting in the reduction of pain. ${ }^{9}$

The EDX microanalysis of the samples showed only traces of active desensitizing chemical agents

\section{References}

1. Banfield N, Addy M. Dentine hypersensitivity: development and evaluation of a model in situ to study tubule patency. J Clin Periodontol. 2004 May;31(5):325-35.

2. Rösing CK, Fiorini T, Liberman DN, Cavagni J. Dentine hypersensitivity: analysis of self-care products. Braz Oral Res. 2009;23 Suppl 1:56-63.

3. Winston AE, Charig AJ, Thong S. Mechanism of action of a desensitizing fluoride toothpaste delivering calcium and phosphate ingredients in the treatment of dental hypersensitivity.
(Sr and P). Si (component of abrasive agent) was present on samples treated with different toothpastes. The presence of calcium, carbon, and oxygen could indicate calcium carbonate (abrasive agent), but these ions are also part of the mineral content of the underlying dentin. These results are in accordance with those of other studies in the literature. ${ }^{5,6,9,13}$ In contrast, another study did not find chemical evidence of the active ingredients of desensitizing agents after EDX analysis. ${ }^{5,9}$ Possible reasons for these different results include the variations in product formulations and concentrations and in application methods.

Several factors could have been responsible for the differences between the results of the current study and other studies in the literature, such as the concentration and formulation of the toothpaste and the time and frequency of brushing, as well as the evaluation methods used..$^{3-5}$ Factors such as oral temperature, saliva flow, dental biofilm, and mastication also could have interfered with the action of the desensitizing toothpastes.

Although in vivo models are probably more convincing than in vitro models, the results of this study should be interpreted with caution before extrapolating them to dental practice in humans, considering the nature and limitations of animal experimentation. Despite the study limitations, the results showed significant differences among desensitizing toothpastes in comparison with other groups

\section{Conclusion}

In conclusion, desensitizing toothpastes decreased dentin permeability, although they produced only partial dentin tubule obliteration.

Part III: Prevention of dye penetration through dentin vs a calcium- and phosphate-free control. Compend Contin Educ Dent. 2010 Jan-Feb;31(1):46-8, 50-2.

4. Wang Z, Sa Y, Sauro S, Chen H, Xing W, Ma X, et al. Effect of desensitising toothpastes on dentinal tubule occlusion: a dentine permeability measurement and SEM in vitro study. J Dent. 2010 May;38(5):400-10.

5. Prati C, Venturi L, Valdre G, Mongiorgi R. Dentin morphology and permeability after brushing with different toothpastes 
in the presence and absence of smear layer. J Periodontol. 2002 Feb;73(2):183-90.

6. Kodaka T, Kuroiwa M, Okumura J, Mori R, Hirasawa S, Kobori M. Effects of brushing with a dentifrice for sensitive teeth on tubule occlusion and abrasion of dentin. J Electron Microsc (Tokyo). 2001;50(1):57-64.

7. Pinto SC, Pochapski MT, Wambier DS, Pilatti GL, Santos FA. In vitro and in vivo analyses of the effects of desensitizing agents on dentin permeability and dentinal tubule occlusion. J Oral Sci. 2010;52(1):23-32.

8. Davies M, Paice EM, Jones SB, Leary S, Curtis AR, West NX. Efficacy of desensitizing dentifrices to occlude dentinal tubules. Eur J Oral Sci. 2011 Dec;119(6):497-503.

9. Arrais CA, Micheloni CD, Giannini M, Chan DC. Occluding effect of dentifrices on dentinal tubules. J Dent. 2003 Nov;31(8):577-84.

10. Aranha AC, Pimenta LA, Marchi GM. Clinical evaluation of desensitizing treatments for cervical dentin hypersensitivity. Braz Oral Res. 2009 Jul-Sep;23(3):333-9.

11. Liu H, Hu D. Efficacy of a commercial dentifrice containing $2 \%$ strontium chloride and $5 \%$ potassium nitrate for dentin hypersensitivity: a 3-day clinical study in adults in China. Clin Ther. 2012 Mar;34(3):614-22.

12. Sampaio JE, Rached RS, Pilatti GL, Theodoro LH, Batista LH. Effectiveness of EDTA and EDTA-T brushing on the removal of root surface smear layer. Pesqui Odontol Bras. 2003 Oct-Dec;17(4):319-25.
13. Ozbek M, Dural S, Kanli A, Tuncel M, Orhan K. Morphological evaluation of rat incisor enamel and dentin induced by pregnancy and lactation using a scanning electron microscope. J Vet Med Sci. 2009 Oct;71(10):1273-7.

14. Forssell-Ahlberg K, Brännström M, Edwall L. The diameter and number of dentinal tubules in rat, cat, dog and monkey. A comparative scanning electron microscopic study. Acta Odontol Scand. 1975;33(5):243-50.

15. El Rouby DH, Bashir MH, Korany NS. The effect of lathyrism on dentin structure of the rat incisors: a morphometric and scanning electron microscopic investigation. J Oral Pathol Med. 2010 May;39(5):424-30.

16. Wang Z, Jiang T, Sauro S, Pashley DH, Toledano M, Osorio R, et al. The dentine remineralization activity of a desensitizing bioactive glass-containing toothpaste: an in vitro study. Aust Dent J. 2011 Dec;56(4):372-81.

17. Farmakis ET, Kozyrakis K, Khabbaz MG, Schoop U, Beer F, Moritz A. In vitro evaluation of dentin tubule occlusion by denshield and neodymium-doped yttrium-aluminum-garnet Laser irradiation. J Endod. 2012 May;38(5):662-6.

18. Dourda AO, Moule AJ, Young WG. A morphometric analysis of the cross-sectional area of dentine occupied by dentinal tubules in human third molar teeth. Int Endod J. 1994 Jul;27(4):184-9. 